\title{
Influência do momento da cobrição, em relação à ovulação, na fertilidade e na ocorrência de morte embrionária precoce em eqüinos
}

[Influence of mating time, with respect to ovulation, on fertility and early embryonic death in equines]

\author{
L.E.S. Ferraz ${ }^{1}$, W.R.R. Vicente ${ }^{2}$ \\ ${ }^{1}$ Aluno de pós-graduação - FCAV-UNESP \\ ${ }^{2}$ Faculdades de Ciências Agrárias e Veterinária - UNESP - Jaboticabal, SP
}

\begin{abstract}
RESUMO
Verificou-se a influência do momento da cobrição, em relação à ovulação, na fertilidade e na ocorrência de morte embrionária precoce (MEP) em 405 éguas da raça Puro Sangue Inglês, acompanhadas por 629 ciclos estrais. As éguas foram divididas em cinco grupos, de acordo com o momento da cobrição: grupo I, composto por 79 éguas cobertas entre 48 e 36 horas antes da ovulação; grupo II, com 102 éguas cobertas 36 a 24 horas antes da ovulação; grupo III, com 166 éguas cobertas 24 a 12 horas antes da ovulação; grupo IV, com 185 éguas cobertas até 12 horas antes da ovulação; e grupo $\mathrm{V}$, formado por 97 éguas cobertas até 12 horas após a ovulação. As ovulações foram determinadas por palpação retal e ultrasonografia, realizadas a cada 12 horas. O diagnóstico de gestação foi feito 14 dias após a cobrição com auxílio de ultra-sonografia. Novo exame foi realizado aos 60 dias para verificar ocorrência de MEP. Maiores índices de prenhez foram observados nos grupos III e IV ( $\mathrm{P}<0,06)$. Verificou-se comportamento quadrático da taxa de prenhez em função do momento da cobrição aos 14 dias $\left(\mathrm{R}^{2}=91,0 \% ; \mathrm{P}<0,05\right)$ e aos 60 dias de prenhez $\left(\mathrm{R}^{2}=89,2 \% ; \mathrm{P}<0,05\right)$. Não foi observada diferença entre os grupos para MEP pelo quiquadrado, mas a análise de regressão revelou comportamento quadrático da variável $\left(R^{2}=92,4 \%\right.$; $\mathrm{P}<0,05)$. O melhor momento para cobrição foram as 24 horas que antecederam a ovulação.
\end{abstract}

Palavras-chave: eqüino, cobrição, ovulação, fertilidade, morte embrionária

\begin{abstract}
The effect of time of mating (with respect to time of ovulation) on fertility and early embryonic death (EED) in the equine was quantified. Thoroughbred mares $(n=405)$ were observed during 629 estrous cycles. The mares were divided into five groups: I- 79 mares that were mated between 48 and 36 hours prior to ovulation; II- 102 mares that were mated between 36 and 24 hours prior to ovulation; III- 166 mares that were mated between 24 and 12 hours prior to ovulation; IV- 185 mares that were mated between 12 hours prior to ovulation and the time of ovulation; and V- 97 mares that were mated during the interval from ovulation to 12 hours after ovulation. The occurrence of an ovulation was determined by rectal palpation and ultrasonography, performed every 12 hours. The diagnosis of conception was done 14 days after mating with the help of ultrasonography. Ultrasonography examination to detect EED was done on the $60^{\text {th }}$ day post-mating. Conception rates were highest in groups III and IV $(P<0.06)$. The regression analysis verified a quadratic model for successful pregnancy 14 days $\left(R^{2}=91.0 \% ; P<0.05\right)$ and 60 days $\left(R^{2}=89.2 \%\right.$; $\left.P<0.05\right)$ post-mating. Although groups did not differ significantly in EED,
\end{abstract}

Recebido em 29 de junho de 2004

Aceito em 6 de outubro de 2005

*Endereço para correspondência (mailing address)

Rua Isac Theodoro de Lima, 629 ap. 12

14020-540 - Ribeirão Preto, SP

E-mail: leferraz@uol.com.br

Apoio: FAPESP 
regression analysis verified a quadratic model $\left(R^{2}=92.4 \%\right.$; $\left.P<0.05\right)$. Results suggest that the optimum time for mating is the interval from 24 hours prior to ovulation up to the time of ovulation.

Keywords: equine, mating time, ovulation, fertility, embryonic death

\section{INTRODUÇÃO}

Vários autores relatam que a viabilidade do espermatozóide após a cobrição é de 48 a 72 horas, enquanto o óvulo permanece viável por 6 a 18 horas após a ovulação. Postula-se a realização da cobrição, ou inseminação, em intervalos de 48 horas até a detecção da ovulação ou interrupção do cio. Com a utilização desse manejo, têm sido relatadas taxas de prenhez por ciclo de 39,4\% a 79,0\% (Lima et al., 2000; Vogelsang et al., 1989).

As taxas de prenhez podem variar em função do momento da cobrição em relação à ovulação. Woods et al. (1990), em experimento com 268 éguas, observaram que os animais, quando inseminados três ou mais dias antes da ovulação, apresentaram menor taxa de prenhez do que aqueles inseminados mais próximos à ovulação. Quando trabalharam com éguas ovuladas, verificaram que o grupo inseminado entre zero e 6 horas após a ovulação apresentou maior índice de concepção do que o grupo inseminado entre 18 e 24 horas pós-ovulação. Nenhuma prenhez foi obtida quando as éguas foram cobertas 30 horas após a ovulação.

Dawson (1977) apontou a morte embrionária precoce (MEP), perda do concepto entre a fertilização e 40 dias de gestação, como uma importante causa de redução da fertilidade em éguas.

Estudos sobre perda embrionária tomaram maior impulso com a introdução da ultra-sonografia. Utilizando-se de palpação retal, a incidência estimada de morte embrionária $\mathrm{e}$ a perda fetal precoce em éguas foram entre 7\% e 16\% (Bain, 1969; Merkt e Gunzel, 1979). Por exame ultrasonográfico, realizado entre 11 e 50 dias de prenhez, situaram-se entre $5 \%$ e $24 \%$ (Ginther et al., 1985; Chevalier e Palmer, 1982; Woods et al., 1987).

Segundo Kenney (1978), nenhuma categoria de égua (lactante, virgem ou vazia) tem sido identificada como especialmente susceptível à MEP, no entanto éguas lactantes têm incidência relativamente maior de MEP quando cobertas no cio do potro, o que não é verificado quando a cobrição se dá nos cios subseqüentes.

O diagnóstico da MEP se faz por palpação retal e exames ultra-sonográficos seriados, quando se verifica ausência da vesícula embrionária, ou, em alguns casos, observam-se alterações na morfologia da vesícula embrionária, tais como, diminuição do diâmetro, irregularidades do contorno e ausência de batimentos cardíacos do embrião a partir de 25 dias (Ginther et al., 1985; Chevalier e Palmer, 1982). Outros indicativos são a presença de líquido uterino e a mobilidade prolongada da vesícula. Morte embrionária antes de 20 dias de gestação pode ocorrer sem que essas anormalidades sejam observadas (Ginther et al., 1985).

Possíveis causas de MEP incluem fatores endócrinos, anormalidades do oviduto ou ambiente uterino (endometrites), idade da égua, estresse, deficiência nutricional, temperatura ambiente, garanhão e defeitos no embrião. Poucas dessas causas têm sido corretamente investigadas (Ball, 1988).

Papa et al. (1998), ao acompanharem a gestação de 128 éguas Puro Sangue Inglês e Quarto de Milha, com o intuito de investigar a ocorrência de MEP, observaram taxa de 13,3\%. Concluíram que o principal fator envolvido seria algum grau de comprometimento do endométrio (endometrite), afastando a possibilidade de deficiência hormonal.

Van Niekerk e Van Niekerk (1998) verificaram a influência da nutrição na ocorrência de MEP. Observaram $35,7 \%$ de MEP em éguas alimentadas com dieta pobre em proteína e 7,3\% em animais que receberam níveis adequados de proteína.

Koskinen et al. (1990), ao estudarem a fertilidade em 28 éguas cobertas entre zero e 27 horas pósovulação, observaram 13 prenhes (46\%). Entre essas, verificaram cinco casos de MEP, o que reduziu a taxa de prenhez para $29 \%$. Os autores concluíram que o óvulo permaneceu em condições de ser fecundado até 18 horas após a 
ovulação, porém a alta incidência de morte embrionária sugeriu que a viabilidade do embrião poderia ser diminuída.

O objetivo deste trabalho foi verificar a influência do momento da cobertura em relação ao momento da ovulação nos índices de concepção e na ocorrência de morte embrionária precoce.

\section{MATERIAL E MÉTODOS}

Foram utilizadas 405 fêmeas eqüinas da raça Puro Sangue Inglês (PSI), com idades entre 3 e 18 anos, observadas em 629 ciclos estrais, com retrospecto reprodutivo satisfatório, em atividade sexual, bom estado nutricional e consideradas hígidas, após avaliação clínica por exame físico. Todas as observações foram conduzidas entre agosto e dezembro, época que compreende a estação de monta do Puro Sangue Inglês, entre os anos de 1995 e 2002.

As éguas, mantidas em pastagens de coast cross (Cynodon dactilon), receberam suplementação alimentar, constituída de ração comercial, aveia, alfafa e sal mineralizado, duas vezes ao dia.

Os sete garanhões utilizados, antes da respectiva estação de monta, foram submetidos à avaliação clínica envolvendo exame físico da genitália externa e dos membros locomotores. A libido e a capacidade de realizar o coito foram observadas no momento da colheita do sêmen, avaliado quanto ao volume, à concentração e à motilidade (Andrade, 1983).

A detecção do cio foi feita por palpação transretal e por exame de ultra-sonografia (US), sendo a rufiação realizada somente em casos específicos, quando se pretendia verificar a aceitação do garanhão pela fêmea. As éguas foram submetidas a exame de palpação retal e US com Scanner modelo $450^{1}$, equipado com transdutor linear de $5 \mathrm{MHz}^{1}$, a cada 12 horas após o início do estro, para controle folicular e verificação da ovulação (Carnevale et al., 1988).

As fêmeas eram encaminhadas à cópula ao apresentarem folículo pré-ovulatório acima de $35 \mathrm{~mm}$ de diâmetro, com flutuação grau 3 ou 4 . Nos casos em que havia ovulação e a égua ainda

${ }^{1}$ Pie Medical, Holanda. não tinha sido acasalada, providenciava-se a cobrição imediata. Antes procedia-se à higienização da vulva.

As éguas foram distribuídas em cinco grupos experimentais, de acordo com o momento da cópula em relação à ovulação. Essa distribuição deu-se ao acaso, e cada égua foi submetida ao coito uma única vez, durante o estro.

No grupo I, as éguas foram submetidas à cobrição entre 48 e 36 horas antes da ovulação; no grupo II, a cópula deu-se entre 36 e 24 horas antes da ovulação; no grupo III, entre 24 e 12 horas antes da ovulação; no grupo IV, entre 12 horas e zero hora antes do momento da ovulação; e, no grupo $\mathrm{V}$, entre zero e 12 horas após a ovulação.

O diagnóstico de gestação foi feito por meio de exame ultra-sonográfico no $14^{\circ}$ e $60^{\circ}$ dia após a cobrição, com o objetivo de verificar a ocorrência de MEP.

Aplicou-se o teste do qui-quadrado para as variáveis taxas de concepção aos 14 dias, de morte embrionária precoce e de prenhez aos 60 dias, em função do momento de cobrição $(\mathrm{P}<0,06)$. Foi também realizada análise de regressão para encontrar um padrão de comportamento das variáveis estudadas em função do tempo (grupos). Aos grupos foram atribuídos valores de tempo. $\mathrm{O}$ modelo quadrático foi o que apresentou o maior $\mathrm{R}^{2}$, com $\mathrm{P}<0,06)$.

Cada um dos garanhões cobriu um grupo de éguas que também foi analisado separadamente e comparado pelo qui-quadrado para identificar a influência do garanhão.

\section{RESULTADOS}

As taxas de concepção aos 14 dias após a cópula, de prenhez aos 60 dias e de MEP, num total de 629 estros, estão na Tab. 1.

Pelo teste qui-quadrado não foram verificadas diferenças nas taxas de prenhez aos 14 dias e de MEP em função do momento da cobrição. Quanto à taxa de prenhez aos 60 dias, houve diferença entre o grupo I e os grupos III e IV $(\mathrm{P}<0,06)$. 
A taxa de concepção em função do tempo (Fig. 1) comportou-se de forma quadrática e pode ser expressa pela equação: \% concepção $14 \mathrm{~d}=42,66$ $+18,83 \mathrm{t}-2,99 \mathrm{t}^{2}$, com $\mathrm{R}^{2}=91,0 \%$ e $\mathrm{P} \leq 0,05$. A taxa de concepção aumentou à medida que a cobrição de ocorreu até um pouco antes de 12 horas da ovulação e diminuiu daí em diante.

Tabela 1. Taxas de concepção aos 14 dias, de prenhez aos 60 dias e de morte embrionária precoce (MEP) em éguas Puro Sangue Inglês, submetidas à cópula em diferentes momentos do estro

\begin{tabular}{|c|c|c|c|c|}
\hline Grupo & Estros & $\begin{array}{l}\text { Concepção } \\
\text { aos } 14 \text { dias }^{*}\end{array}$ & $\begin{array}{c}\text { Prenhez } \\
\text { aos } 60 \text { dias }\end{array}$ & $\mathrm{MEP}^{* *}$ \\
\hline I (48/36 h pré-ovulação) & 79 & $46(58,2 \%)$ & $38(48,1 \%)^{\mathrm{A}}$ & $8(17,4 \%)$ \\
\hline II (36/24 h pré-ovulação) & 102 & $71(69,6 \%)$ & $61(59,8 \%)^{\mathrm{AB}}$ & $10(14,1 \%)$ \\
\hline III (24/12 h pré-ovulação) & 166 & $117(70,5 \%)$ & $105(63,3 \%)^{\mathrm{B}}$ & $12(10,3 \%)$ \\
\hline IV (12/0 h pré-ovulação) & 185 & $132(71,4 \%)$ & $122(65,9 \%)^{\mathrm{B}}$ & $10(7,6 \%)$ \\
\hline V (0/12 h pós-ovulação) & 97 & $60(61,9 \%)$ & $54(55,7 \%)^{\mathrm{AB}}$ & $6(10,0 \%)$ \\
\hline Total & 629 & $426(67,7 \%)$ & $380(60,4 \%)$ & $46(10,8 \%)$ \\
\hline
\end{tabular}

*Porcentagem em função do número de ciclos utilizados; ** porcentagem em função do número de prenhezes verificadas aos 14 dias Médias seguidas por letras distintas na coluna diferem entre si $(\mathrm{P} \leq 0,06)$ pelo teste qui-quadrado.

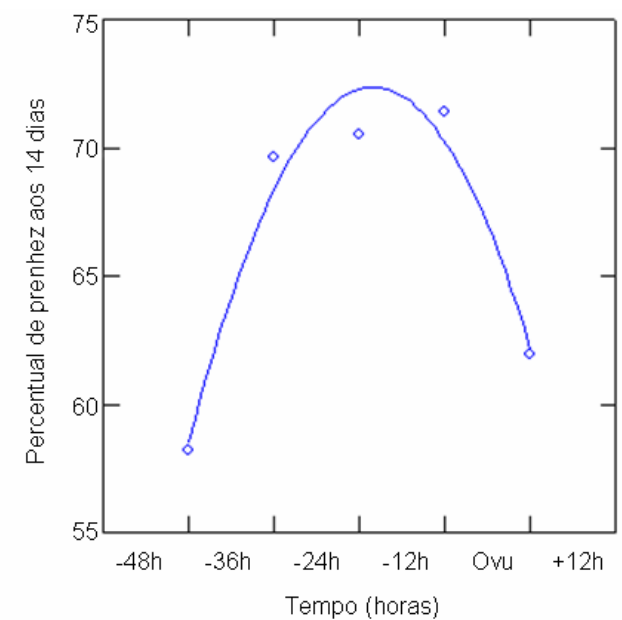

Figura 1. Taxa de concepção segundo o momento da cópula em relação à ovulação, em éguas PSI 14 dias após a cobrição.

A taxa de MEP em função do momento de cobrição está representada na Fig. 2. Ao contrário do observado para a taxa de concepção aos 14 dias, a ocorrência de MEP diminuiu até bem próximo à ovulação e aumentou a partir daí. O modelo de regressão quadrático também foi o que melhor explicou o comportamento da ocorrência de MEP em função do momento da cobrição, sendo representado pela equação: $\% \mathrm{MEP}=24,52-7,49 \mathrm{t}+0,89 \mathrm{t}^{2}, \mathrm{com} \mathrm{R}^{2}=89,2 \%$ e $\mathrm{P}<0,05$.
A união dessas duas características (concepção aos 14 dias e MEP) estabelece que as diferenças entre os percentuais de prenhez aos 60 dias após a cópula acentuam-se, pois maior freqüência de MEP ocorre justamente nos grupos com menor taxa de concepção aos 14 dias. Assim, as maiores taxas de prenhez aos 60 dias foram obtidas nos grupos III e IV, quando as éguas foram submetidas ao coito nas 24 horas imediatamente anteriores à ovulação (Fig. 3).

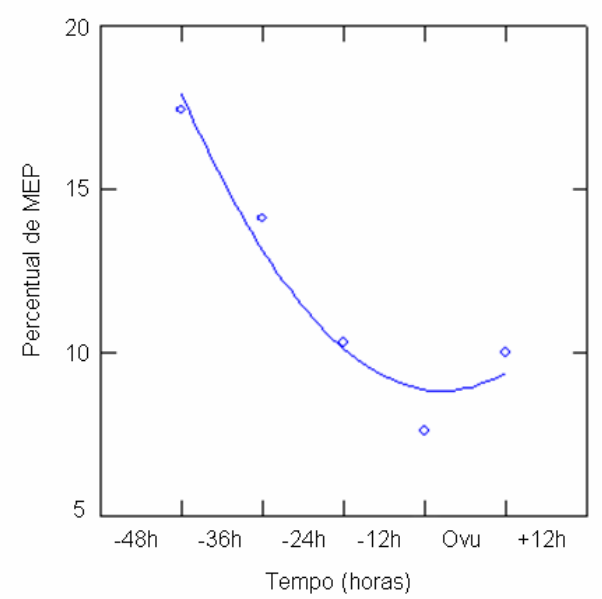

Figura 2. Ocorrência de morte embrionária precoce (MEP) segundo o momento da cópula em relação à ovulação, em éguas PSI entre $14 \mathrm{e}$ 60 dias de prenchez. 


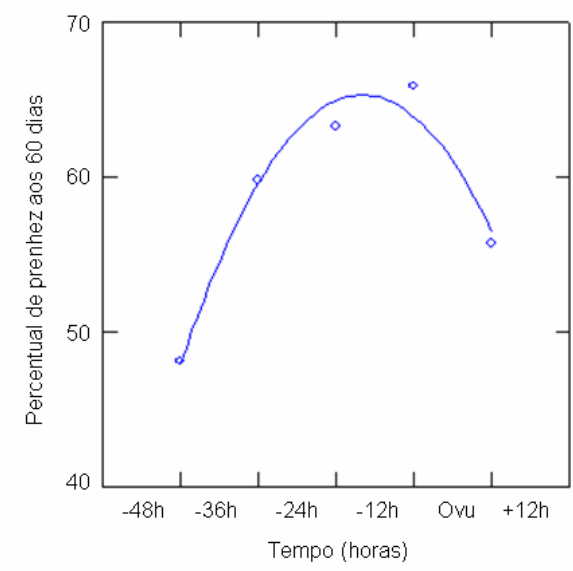

Figura 3. Taxa de prenhez segundo o momento da cópula em relação à ovulação, em éguas PSI 60 dias após a cobrição.

A análise de regressão revelou que o percentual de fêmeas prenhes aos 60 dias também se comporta de forma quadrática, representada pela equação: \% prenhez $60 \mathrm{~d}=29,82+21,28 \mathrm{t}-$ $3,19 \mathrm{t}^{2}$, com $\mathrm{R}^{2}=92,4 \%$ e $\mathrm{P}<0,05$

Não foi observada diferença entre os garanhões quanto às taxas de concepção aos 14 dias, prenhez aos 60 dias e ocorrência de MEP.

\section{DISCUSSÃO E CONCLUSÕES}

O fato de as éguas terem sido distribuídas em grupos conforme o momento da cópula não interferiu negativamente na fertilidade, pois a totalidade das observações realizadas apresentou $67,7 \%$ de taxa de concepção aos 14 dias e 60,4\% de taxa de prenhez aos 60 dias. Essas taxas são superiores às encontradas por Morris e Allen (2002), que, em levantamento realizado na GrãBretanha, também com éguas PSI, verificaram $15,9 \%$ de taxa de prenhez aos 15 dias. Woods et al. (1987) relataram 54\% de prenhez 14 dias após a cobertura. Cabe ressaltar que as condições climáticas na Grã-Bretanha são mais rigorosas, podendo influenciar negativamente na performance reprodutiva, principalmente no início da estação de monta.

Quanto à ocorrência de MEP, observou-se taxa de $10,8 \%$ entre 14 e 60 dias de prenhez, resultado semelhante aos de Morris e Allen (2002) e Woods et al. (1987), 10,3\% e 13\%, respectivamente. Chevalier-Clément (1989) observou, em 3740 éguas prenhes, 8,9\% de MEP no intervalo entre 22 e 44 dias de prenhez. Duarte et al. (2002) verificaram 8,5\% de ocorrência de MEP em éguas Quarto de Milha até o $50^{\circ}$ dia de prenhez, sendo que em $63,2 \%$ a MEP ocorreu entre o $11^{\circ}$ e o $20^{\circ}$ dia de gestação.

Pelo comportamento quadrático das variáveis estudadas, observa-se aumento da eficiência reprodutiva à medida que a cópula ocorreu mais próxima à ovulação e diminuição quando as éguas já haviam ovulado.

Woods et al. (1990) verificaram que éguas cobertas até três dias apresentavam melhores taxas de concepção que aquelas acasaladas quatro dias antes da ovulação. Observaram que éguas cobertas antes da ovulação tiveram melhores taxas de concepção que as acasaladas no dia da ovulação. Verificaram também que, em éguas acasaladas até 12 horas após a ovulação, a taxa de concepção era similar à do grupo préovulatório e que éguas acasaladas 30 horas após não se tornaram prenhes. Koskinen et al. (1990) também comprovaram o curto período em que o óvulo permanece viável após a ovulação, ao verificarem que, até 18 horas após a ovulação, as éguas tornaram-se prenhes, e nenhuma prenhez foi obtida no grupo coberto com mais de 24 horas da ovulação.

Lima et al. (2000), ao estudarem a influência do número de inseminações por ciclo na taxa de concepção, inseminando éguas em diferentes momentos do cio, obtiveram taxas de prenhez que variaram de $51,3 \%$ para éguas cobertas 48 horas antes da ovulação a $63,3 \%$, obtidas quando eram inseminadas 24 horas pré-ovulação.

A variação dos índices de concepção e prenhez, conforme o momento do coito e da ovulação, pode ser explicada pelo tempo de viabilidade dos gametas. $\mathrm{O}$ espermatozóide do garanhão permanece viável por até 72 horas, com melhores resultados quando se utilizam cobrições a cada 48 horas, e o óvulo é viável por até 18 horas (Hunter, 1990). No entanto, Woods et al. (1990) obtiveram prenhez em éguas inseminadas quatro dias antes da ovulação.

Sabe-se que, próximo ao momento da ovulação, observam-se maiores taxas de prenhez e menores de MEP. Isso pode ser explicado pela senilidade 
dos gametas, pois, ao se acasalarem éguas dois dias, ou mais, antes da ovulação, a fertilização ocorreria a partir de espermatozóides velhos, o mesmo acontecendo com o óvulo, nas éguas ovuladas (Blue, 1981).

$\mathrm{O}$ fato de o presente experimento ter limitado o período de acasalamento ao intervalo de 48 horas pré-ovulação e 12 horas pós-ovulação justificaria a manutenção dos índices de concepção em níveis elevados (acima de 50\%) em todos os grupos experimentais. Morris e Allen (2002) observaram que, apesar de éguas e garanhões PSI não serem selecionados a partir da fertilidade, mas sim pela combinação entre pedigree e desempenho atlético, altos níveis de fertilidade ocorrem com a adoção de manejo reprodutivo intensivo.

Ao estudar a ocorrência de MEP em função do momento da cópula, verifica-se que maior número de MEP acontece no grupo de éguas ovuladas e nos grupos em que as fêmeas foram acasaladas no período mais distante da ovulação (48 a 24 horas pré). Woods et al. (1990) e Koskinen et al. (1990) verificaram maior ocorrência de MEP nas éguas cobertas ovuladas, sendo que os últimos autores indicaram $38 \%$ de MEP.

Hunter (1990) levantou a hipótese de os gametas conservarem a capacidade de serem fertilizados por mais tempo, no entanto o ambiente uterino poderia não estar propício à implantação do embrião quando a fertilização ocorresse distante da ovulação, explicando as menores taxas de concepção e a maior ocorrência de MEP. Krackow (1997), em sua teoria sobre assincronia do desenvolvimento de embriões masculinos e femininos em mamíferos, postulou que alterações do estádio de desenvolvimento do ambiente uterino por fatores hormonais ou externos, em relação aos blastocistos, influenciariam as taxas de concepção e de MEP. Dessa maneira, embriões mais ou menos desenvolvidos teriam menor chance de sucesso na implantação. Assim, não é só o momento da cópula em relação à ovulação que estaria envolvido na determinação das taxas de fertilidade e de ocorrência de MEP. A possibilidade de os garanhões estarem afetando os resultados foi descartada, pois não foram observadas diferenças entre os garanhões utilizados, uma vez que eles, além de terem sido examinados previamente, eram reconhecidamente férteis.

Conclui-se que a cobrição realizada nas 24 horas que antecedem a ovulação resulta em maior eficiência reprodutiva e que as taxas de concepção aos 14 dias, de prenhez aos 60 dias e de MEP estão fortemente relacionadas ao momento da cobrição associada ao momento da ovulação.

\section{REFERÊNCIAS BIBLIOGRÁFICAS}

ANDRADE, L.S. Avaliação reprodutiva dos garanhões. In: Fisiologia e manejo da reprodução eqüina. Recife, 1983. cap.7.3, p.140141.

BAIN, A.M. Foetal losses during pregnancy in Thoroughbred mares: A record of 2562 pregnancies. Irish Vet. J., v.17, p.155-158, 1969.

BALL, B.A. Embryonic loss in mares: Incidence, possible causes, and diagnostic considerations. Vet. Clin. North Am.: Equine Pract., v.4, p.263290, 1988.

BLUE, M.G.A citogenetical study of prenatal loss in the mare. Theriogenology, v.15, p.295309, 1981.

CARNEVALE, E.M.; McKINNON, A.O.; SQUIRES, E.L. Ultrasonic characteristics of the preovulatory follicle directly proceeding and during ovulation in the mare. Theriogenology, v.29, p.232, 1988.

CHEVALIER, F.; PALMER, E. Ultrasonic echography in the mare. J. Reprod. Fertil., suppl., v.32, p.423-30, 1982.

CHEVALIER-CLÉMENT, F. Pregnancy loss in the mare. Anim. Reprod. Sci., v.20, p.231-244, 1989.

DAWSON, F.L.M. Recent advances in equine reproduction. Equine Vet. J., v.9, p.4-11, 1977.

DUARTE, M. B.; VIEIRA, R.C.; CARNEIRO e SILVA, F. O. Incidência de perda de prenhez até o $50^{\circ}$ dia em éguas quarto de milha. Ciênc. Rural, v. 32, p.643-647, 2002.

GINTHER, O.J.; BERGFELT, D.R.; LEITH, G.S. et al. Embryonic loss in mares: Incidence 
and ultrasonic morphology. Theriogenology, v.24, p.73-86, 1985

HUNTER, R.H.F. Gamete lifespans in the mare's genital tract. Editorials. Equine Vet. J., v.22, p.378-379, 1990.

KENNEY, R. M. Cyclic and pathologic changes of the mare endometrium as detected by biopsy, with a note on early embryonic death. J. Am. Vet. Med. Assoc., v.172, p.241, 1978

KOSKINEN, E.; LINDEBERG, H.; KUNTSI, H. et al. Fertility of mares after postovulatory insemination. Zentralbl Veterinarmed A, v.37, p.77-80, 1990.

KRACKOW, S. Further evaluation of the developmental asynchrony hypothesis of sex ratio variation. Appl. Anim. Behav. Sci., v.51, p.243-50, 1997.

LIMA, M.C.C., SILVA FILHO, J.M., CARVALHO, G.R. et al. Efeito do número de inseminações artificiais por ciclo sobre a fertilidade de éguas inseminadas com sêmen eqüino diluído, resfriado a $20^{\circ} \mathrm{C}$ e transportado. Rev. Bras. Zootec., v.29, p.1649-1653, 2000.

MERKT, H.; GUNZEL, A. A survey of early pregnancy losses in West German Thoroughbred mares. Equine Vet. J., v.11, p.256-258, 1979.
MORRIS, L.H.A., ALLEN, W.R. Reproductive efficiency of intensively managed Thoroughbred mares in Newmarket. Equine Vet. J., v.34, p.5160, 2002.

PAPA, F.O.; LOPES, M.D.; ALVARENGA, M.A. et al. Early embryonic death in mares: clinical and hormonal aspects. Braz. J. Vet. Res. Anim. Sci., v.35, p.170-173, 1998.

VAN NIEKERK, F.E; VAN NIEKERK, C.H. The effect of dietary protein on reproduction in the mare. VII. Embryonic development, early embryonic death, foetal losses and their relationship with serum progestagen. J. S. Afr. Vet. Assoc., v.69, p.150-5, 1998.

VOGELSANG, M.M.; VOGELSANG, S.G.; LINDSEY, B.R. et al. Reproductive performance in mares subjected to examination by diagnostic ultrasound. Theriogenology, v.32, p.95-103, 1989.

WOODS, G.L.; BAKER, C.B.; BALDWIN, J.L. et al. Early pregnancy loss in broodmares. $J$. Reprod. Fertil. suppl, v.35, p.455-9, 1987.

WOODS, J.; BERGFELT, D.R.; GINTHER, O.J. Effects of time of insemination relative to ovulation on pregnancy rate and embryonic-loss rate in mares. Equine Vet. J., v.22, p.410-5, 1990. 